trimethoprim has remained the same $(26 \%)$ in the six months before the change and in the six months afterwards. Resistance to sulphonamides has dropped from $40 \%$ to $37^{\circ}$. Between 1983 and 1984 the total amount of trimethoprim prescribed in the hospital increased by $31 \%$. These findings are in accord with our previous data that there is no evidence that adding a sulphonamide to trimethoprim discourages resistance.

We would like to invite Dr Maskell to perform the following experiments: select cultures of either fully sensitive or sulphonamide resistant (trimethoprim sensitive) enterobacteriaceae, expose them to trimethoprim of the sort of concentration-for example, $256 \mu \mathrm{g} / \mathrm{ml}$ - to which strains are highly resistant, and see if any resistant variants can be selected. She will find few such variants from either type of culture, and the few bacteria that may struggle through will be grossly defective and probably not pathogenic.

Surely the time has come to withdraw cotrimoxazole for urinary and many other infections, such as typhoid. The major active component of co-trimoxazole is trimethoprim. It is effective and safe. It should be used alone unless reliable evidence is presented that sulphonamides have a contribution. Dr Maskell provides no such data.

R W LACEY R G LOKER

Department of Microbiology, University of Leeds,
Leeds LS2 9J T

J COOKE

Department of Pharmacy,

Leeds Western Health Authority,

Leeds

SIR,-Dr Rosalind Maskell postulated that the decline in resistance to trimethoprim resulted from a decrease in the use of trimethoprim alone as compared with cotrimoxazole. The rationale behind this may $\mathrm{R} T$ CALVERT

use of plain trimethoprim must be considered only in the context of the far greater amount of co-trimoxazole used overall. Any alteration in the pattern of resistance to trimethoprim is surely more likely to result from co-trimoxazole.

Medical Department,

Southampton SO3 $3 \mathrm{JD}$

1 Brumfitt W, Hamilton-Miller JMT, Wood A. Evidence for a slowing in trimethoprim resistance during $1981-$ a comparison with earlier years. $\mathcal{J}$ Antimicrob Chemother 1983;11:503-9.

2 Huovinen P, Mantyjarvi R, Toivanen P. Trimethoprim $\mathrm{res}$

3 Knothe $\mathrm{H}$. The effect of trimethoprim-sulphonamide, trimethoprim and sulphonamide on the occurrence trimesioprim and sulphonamide on the occurrence of resistant enterobacteriaceae in hu
flora. Infection $1979 ; 7$ (suppl 4):321-3.

4 Amyes SGB. The detection and incidence of transferable trimethoprim resistance. Health Bulletin 1983;41:99-107.

SIR,-The letter from Dr Rosalind Maskell (12 January, $p$ 156) has prompted us to look at the resistance to trimethoprim of Enterobacteriaceae causing acute urinary tract infections in family practice in north Hampshire.

Since 1975 this laboratory has tested and reported trimethoprim and sulphonamide sensitivities separately. Between 1976 and 1980 intermittent studies of these organisms were made, and "best guess" antimicrobials recommended to general practitioners in our area. Since March 1980 trimethoprim alone has been recommended. From June 1983 information about these organisms has been stored on microcomputer discs. The results are summarised in the table. The columns for co-trimoxazole and trimethoprim are practitioners' prescription intentions for patients who subsequently proved to have significant bacteriuria; the drugs include both generic and proprietary preparations.

We suggest that, in spite of a large increase in the use of trimethoprim alone, there has

Resistance to trimethoprim of Enterobacteriaceae from acute urinary tract infections in family practice and the prescribing intentions of general practitioners

\begin{tabular}{|c|c|c|c|c|}
\hline & \multirow{2}{*}{$\begin{array}{c}\text { Total } \\
\text { No of } \\
\text { organisms }\end{array}$} & \multirow{2}{*}{$\begin{array}{l}\text { No }\left({ }^{\prime}{ }_{0}\right) \\
\text { resistant to } \\
\text { trimethoprim }\end{array}$} & \multicolumn{2}{|c|}{ No of prescriptions for: } \\
\hline & & & Co-trimoxazole & Trimethoprim \\
\hline $\begin{array}{l}1976 \text { (Feb-Mar) } \\
1980 \text { (Mar-Jul) } \\
1983 \text { (Jul-Dec) } \\
1984 \text { (Jan-Jun) } \\
1984 \text { (Jul-Dec) }\end{array}$ & $\begin{array}{l}297 \\
254 \\
849 \\
787 \\
797\end{array}$ & $\begin{array}{r}9(3 \cdot 0) \\
19(7 \cdot 5) \\
39(4 \cdot 6) \\
37(4 \cdot 7) \\
43(5 \cdot 4)\end{array}$ & $\begin{array}{r}57 \\
123 \\
93 \\
96\end{array}$ & $\begin{array}{r}51 \\
276 \\
265 \\
357\end{array}$ \\
\hline
\end{tabular}

be unsound and is not supported by other published studies. ${ }^{12}$ There is evidence that the sulphonamide component does not prevent trimethoprim resistance developing when co-trimoxazole is used. The use of either trimethoprim or co-trimoxazole has been shown to remove faecal coliforms from the gut flora, which return, fully sensitive, when treatment is discontinued. The use of a sulphonamide alone, however, quickly selects resistant faecal coliforms. ${ }^{3}$ Furthermore, the discussion should not be confined to these two drugs, the transfer of plasmids conferring both ampicillin and trimethoprim resistance being the probable explanation for a concurrent increase in ampicillin usage and trimethoprim resistance in some hospitals. ${ }^{4}$

Dr Maskell reports the ratio of the use of co-trimoxazole to trimethoprim at St Mary's Hospital, Portsmouth as being $16: 1$ in 1982 and $19: 1$ in 1984. This small reduction in the prim resistance. Therefore we shall continue to recommend the use of trimethoprim alone in this situation, particularly to prevent patients receiving an unnecessary sulphonamide.

P A Boswell

Microbiology Department, Basingstoke District Hospital,
Basingstoke, Hants RG24 9NA SUSAN HINDER

\section{Prevention of meningitis in head injury}

SIR,-We were surprised at Dr Sanderson's suggestion (24 November 1984, p 1456) that chloramphenicol might supersede sulphonamides in preventing meningitis in fractures of the base of the skull. While toxicity from chloramphenicol is uncommon, the serious
Duphar Laboratories Ltd

ness and irreversibility of such toxicity would discourage many from using it in other than life threatening infections. Our experience and considerations of bacterial sensitivity and antibiotic pharmacokinetics suggest that the use of chloramphenicol is not justified.

Although this bony injury is relatively common ( 50 such cases having been admitted to Bristol Road Infirmary in 1983), with our standard prophylaxis of sulphonamide plus benzylpenicillin no case of meningitis secondary to such an injury has been detected in our laboratory in the past five years. Thus we are faced with a recommendation to change a regimen that seems to work well, on the grounds of changing patterns of bacterial antibiotic resistance.

Our reading of Dr Sanderson's references on antibiotic resistance suggests very different figures from those in his table. For Haemophilus influenzae he appears to have extracted the resistance rates for chloramphenicol and sulphonamide $\left(8^{\circ} \circ\right.$ and $51^{\circ} \%$ respectively) from table I of his reference. ${ }^{1}$ This table deals with a selected group of strains which showed reduced inhibition zones to any of the antibiotics tested. In the text the overall resistance rates were concluded to be $1.03^{\circ}$, for chloramphenicol and $1.5^{\circ}$ for sulphonamide. In considering Streptococcus pneumoniae, ${ }^{2} \mathrm{Dr}$ Sanderson sets a breakpoint for resistance ( $>2 \mathrm{mg} / \mathrm{l}$ ) which appears unreasonably low, in that all the strains tested were inhibited by $4 \mathrm{mg} / 1$ of chloramphenicol and by $8 \mathrm{mg} / 1$ of sulphonamide, and these concentrations are readily surpassed in serum and in cerebrospinal fluid after standard doses whether or not the meninges are inflamed.

If it is felt that antibiotic cover must be extended to include reliably Staphylococcus aureus we suggest that trimethoprim (which also achieves therapeutically effective concentrations in cerebrospinal fluid and to which almost all strains of the three pathogens are sensitive) may be added to the sulphonamide (as co-trimoxazole) in prophylaxis; cefuroxime alone is another possibility. At present, however, there seems to be little evidence of a need to change a satisfactory prophylactic regimen.

M J KeLLY

J H Paton

Bristol Royal Infirmary,

Bristol BS2 8HW

1 Philpott-Howard J, Williams JD. Increase in antibiotic resistance in Haemophilus influenzae in the United Kingdom since 1977: report of study group.

2 Cooksey RC, Facklam RR, Thornsberry C. Antimicrobial sensitivity patterns of Streptcooccus pneumon

3 Barling RWA, Selkon JB. The penetration of antibiotics into cerebrospinal fluid and brain tissue. $f$ Antimicrob Chemother $1978 ; 4: 203-27$.
f

\section{How soon after myocardial infarction} should plasma lipid values be assessed?

SIR, - We have read with interest the article by $\operatorname{Dr} R \mathrm{E} J$ Ryder and others (15 December, p 1651) about the evolution of serum lipid values during the acute phase of myocardial infarction and three months later. We have measured serum lipid values in 12 men with mvocardial infarction. Sampling was performed on admission within 12 hours after the onset of symptoms and $2,4,6,8,10$, and 30 days after admission. The sample on the 30 th day was obtained at an outpatient clinic two weeks after discharge. Contrary to the results of Dr Rvder and others, we ohserved 
Serum lipid levels at admission (day 0 ), and 2, 4,6,8,10, and 30 days after acute myocardial infarction. Results are means (and $S D$ )

\begin{tabular}{|c|c|c|c|c|c|c|c|}
\hline Days: & 0 & 2 & 4 & 6 & 8 & 10 & 30 \\
\hline $\begin{array}{l}\text { Total cholesterol } \\
\text { (mmol/1) } \\
\text { HDL cholesterol }\end{array}$ & $4.53(1.08)$ & $4 \cdot 14(1 \cdot 00)$ & $4 \cdot 44(1 \cdot 11)$ & $4.67(1.09)$ & $4.94(1.08)$ & $5 \cdot 16(1 \cdot 13)$ & $5.94(1.43)^{*}$ \\
\hline $\begin{array}{l}(\mathrm{mmol} / \mathrm{l}) \\
\text { Triglycerides }(\mathrm{mmol} / \mathrm{l})\end{array}$ & $\begin{array}{l}0.97(0.23) \\
1.29(0.52)\end{array}$ & $\begin{array}{l}0.88(0.21) \\
1.38(0.63)\end{array}$ & $\begin{array}{l}0.85(0.17) \\
1.49(0.80)\end{array}$ & $\begin{array}{l}0.87(0.12) \\
1.53(0.64)\end{array}$ & $\begin{array}{l}0.94(0.14) \\
1.62(0.75)\end{array}$ & $\begin{array}{l}0.99(0.16) \\
1.86(0.96)_{+}^{+}\end{array}$ & $\begin{array}{l}1 \cdot 09(0 \cdot 17) \dagger \\
2 \cdot 13(1 \cdot 12) \ddagger\end{array}$ \\
\hline
\end{tabular}

* Significantly raised compared with admission $p<0.025$. +Significantly raised compared with fourth day after

admission $\mathrm{p}<0.01$. \$Significantly raised compared with admission $\mathrm{p}<0.05$.
Conversion: SI to traditional units-Cholesterol: $1 \mathrm{mmol} / 1 \approx 38.6 \mathrm{mg} / 100 \mathrm{ml}$. Triglycerides: $1 \mathrm{mmol} / 1 \approx 88.5 \mathrm{mg} /$ $100 \mathrm{ml}$

a significant rise in serum triglyceride concentration on days 10 and 30 (table), which agreed with the findings of Ballantyne et $a l^{1}$ and Heldenburg et al. ${ }^{2}$ In our patients, after a transient decrease, total cholesterol concentration increased significantly. Serum high density lipoprotein (HDL) cholesterol also showed a slight decrease with a further increase one month after admission. Details of HDL subfractions and apoproteins A and B are reported elsewhere. ${ }^{3}$

Several factors can influence serum lipid concentrations during the treatment of acute myocardial infarction in the coronary care unit: stress, bed rest, heparin administration (our patients received heparin for three to eight days after admission), other drugs such as diuretics, diet changes, and stopping smoking. After discharge the home diet, an increase in physical activity, and in some cases a return to smoking and alcohol abuse might modify serum lipid concentrations.

Patients with homozygous and heterozygous forms of familial hypercholesterolaemia are easy to identify at the time they enter hospital, but familial multiple typ hyperlipoproteinaemia and polygenic hyper cholesterolaemia are not easily diagnosed in most cases. From a practical point of view, because patients with presumed hyperlipoproteinaemia should not receive drug treatment until after three or four months of diet treatment, the diagnosis of slight or moderate hyperlipidaemia seems not to be essential at this time. In many clinics, patients who have suffered an acute myocardial infarction are placed on diets low in saturated fats and cholesterol irrespective of their serum lipid values. The reason for diagnosing raised serum lipid values in these patients is for screening their relatives, as stated by Professor M F Oliver (p 1641).

J RubiÉS-Prat J JOVEN

Department of Medicine

Universidad Autónoma de Barcelona,

Hospital Germans

1 Ballantyne FC, Melville DA, McKenna JP, Morrison BA, Ballantyne D. Response of plasma lipoproteins and acute phase proteins to myocardia
nfarction. Clin Chim Acta 1979;99:85-92. Heldenburg D, Rubenstein A, Levtov O, Berns L,
Werbin B, Tamir L. Serum lipids and lipoprotein concentrations during the acute phase of myocardial infarction. Atherosclerosis $1980 ; 35: 433-7$.

3 Joven J, Rubiés-Prat J, Masdeu S, de la Figuera M, Chacon P. Modificaciones de las lipoproteinas de alta densidad durante la fase aguda del infarto de
miocardio. Med Clin (Barc) $1985 ; \mathbf{8 4}: 135-7$.

\section{Drugs taken by mothers in the puerperium}

SIR,-In this interesting survey of drugs (8 December, p 1593) taken by or given to mothers in the puerperium there appear to be a few important omissions. No mothers in hospi- tal are recorded as having been given oxytocin during this period yet it is common practice for those who have had caesarean section to have an infusion of a solution containing oxytocin for two to six hours afterwards.

Also, there is no record of any anaesthetic drugs being administered. Postpartum tubal ligations and also curettage are usually done under general anaesthesia. This is usually induced using barbiturates, which are metabolised over 12-24 hours and so would be important in breast feeding mothers.

I would also like to comment on the remarks about narcotic analgesics. Most of the narcotic analgesics are prescribed by anaesthetists after operative delivery and, though the entry in the medicine card index reads " $4-6$ hourly if required," in many patients the time interval is much longer, and many receive only two or three doses. A distribution of the total dose received in these cases, and especially in those who were breast feeding, would have been more instructive bearing in mind the suggestion mothers. I was not quite sure whether this suggestion was a criticism of present monitoring. I get the impression that all infants are closely monitored, as they need to be. These analgesic drugs have been the preferred drugs for many years, and no obvious side effects have been noted in breast fed infants.

JOHN C MOFFETT

Department of Clinical Anaesthesia Belfast City Hospital,

***The authors reply below.-ED, BMF.

SIR,-We thank Dr Moffett for his queries on oxytocin, barbiturates, and narcotic analgesics. As we mentioned in our paper, we used the charted medicine card index and the nursing notes to obtain information on the drugs received by mothers. Information on oxytocin was not given on either of these in the hospitals surveyed but would, presumably, have been included in the labour notes. The latter were not consulted since our study was purely on postpartum drug treatments. We agree, however, that drugs given at the time of delivery may well pass into colostrum; we do not, however, have any information on the excretion of oxytocin in milk.

Information on drugs used during postpartum surgical procedures was not entered on the medical card indexes or nursing notes and therefore was not recorded in our survey. We agree with Dr Moffett that barbiturates used in anaesthetic induction may theoretically present a subsequent hazard to the suckling infant, although we have no information as to the likelihood of this.

Finally, we agree that analgesics given "as required" are not always administered every for close monitoring of the infants of these four to six hours; however, drugs were included in our tables only when they were given. We have, in fact, data on the frequency of use of all the prescribed drugs on file, although space did not permit such full information to be presented in our paper. With regard to the prescribing of narcotic analgesics to mothers and the monitoring of their infants, we do not wish to criticise practice in the hospitals surveyed. Our general recommendation, however, is that until firm scientific evidence is available on the excretion of levorphanol or papaveretum in milk and the effect of this on the suckling infant it would be prudent to apply the same precautions that are appropriate to other narcotic analgesics.

Clare M Passmore

JAMES C MCELNAY

PATRICK F D'ArCy

Department of Pharmacy,

The Queen's University of Belfast,

Northern Ireland

Fatal multisystemic toxicity associated with prophylaxis with pyrimethamine and sulfadoxine

SIR, - We read with interest the case reported by Dr C D Selby and others (12 January, p 113). We have recently seen a patient who developed toxic epidermal necrolysis, hepatic impairment, disseminated intravascular coagulation, and renal failure with a Gram negative septicaemia after the administration of sulphasalazine for ulcerative proctitis.

The patient, a 28 year old man, whose only other medication was Colifoam rectal application developed a widespread erythematous, maculopapular rash nine days after starting sulphasalazine $3 \mathrm{~g}$ daily. Conjunctival, urethral, and buccal mucosal lesions were pronounced, and over 24 hours the rash developed into classical toxic epidermal necrolysis. Within three days of the onset of the rash the patient had evidence of liver impairment with a serum bilirubin concentration of $34 \mu \mathrm{mol} / 1(2 \cdot 0 \mathrm{mg} / 100 \mathrm{ml}$ ) (normal $2-17 \mu \mathrm{mol} / 1(0 \cdot 12-1.0 \mathrm{mg} / 100 \mathrm{ml})$ ).

The patient was treated with intravenous fluid replacement, hydrocortisone $800 \mathrm{mg}$ intravenously daily, flucloxacillin $2 \mathrm{~g}$ daily, and wet dressings of potassium permanganate. Serum zinc concentration was low $(21 \mathrm{nmol} / \mathrm{l}(32 \mu \mathrm{g} / 100 \mathrm{ml})$ normal 33-98 $\mathrm{nmol} / \mathrm{l}(50-150 \mu \mathrm{g} / 100 \mathrm{ml}))$ and he was started on zinc sulphate $400 \mathrm{mg}$ daily. There was considerable initial improvement despite the extensive area of skin loss (about $80^{\circ} \%$ of body surface area), and it seemed likely that he would recover fully.

Twenty days after the onset of the illness he developed discrete new bullous lesions suggestive of a recurrence of toxic epidermal necrolysis. A biopsy at this time confirmed toxic epidermal necrolysis of the subepidermal type associated with drug reactions. This occurred 10 days after he started tobramycin $80 \mathrm{mg}$ three times daily and ticarcillin $5 \mathrm{~g}$ three times daily for a mixed streptococcal and pseudomonal infection and two days after the development of vesicular lesions on the trunk, which were shown to contain herpes particles on electron microscopy. Herpes particles were also identified from throat swabs. He was started on intravenous acyclovir and the skin lesions were treated with hydrocolloid dressing (Geliperm, Geistlich).

Despite some improvement in his skin, his general condition deteriorated with progressive hepatic impairment, increasing drowsiness, and the development of a Gram negative septicaemia He required intermittent positive pressure ventilation and parenteral nutrition. Unfortunately, he developed disseminated intravascular coagulation and renal failure and died of overwhelming infection 42 days after the start of the illness. 